\title{
Is treatment of type 1 diabetes mellitus (insulin therapy, metabolic control) optimal for preventing cardiovascular autonomic neuropathy?
}

\author{
Łukasz Pawliński', Joanna Gastoł', Mateusz Fiema ${ }^{1}$, Bartłomiej Matejko', Beata Kieć-Wilk', 2 \\ ${ }^{1}$ Department of Metabolic Diseases, University Hospital, Krakow, Poland \\ ${ }^{2}$ Department of Metabolic Diseases, Jagiellonian University Medical College, Krakow, Poland
}

\begin{abstract}
Introduction: Long-term poor metabolic control promotes the occurrence of microvascular complications, such as cardiovascular autonomic neuropathy (CAN) and atherogenic hyperlipidaemia, which translates into increased mortality in patients with type 1 diabetes mellitus (T1DM). The aim of the study was to assess the prevalence of CAN in patients with T1DM in relation to treatment method (continuous subcutaneous insulin infusion, CSII, versus multiple daily injections using pens, MDI) and metabolic control.

Material and methods: The study group comprised 93 adults (60 women, 33 men), mean age 31 years, with T1DM being treated at a local clinical centre from 2011 to 2015 . The presence of CAN, the results of laboratory tests, and anthropometric data were analysed. The subjects were divided into two groups according to treatment method (CSII, MDI).

Results: The median duration of diabetes was 16 years. $61 \%$ of the subjects used MDI and $39 \%$ used CSII. $41 \%$ of the subjects presented with CAN (confirmed with the Ewing test using ProSciCard apparatus), with a significantly lower prevalence in the group of patients treated with CSII $(15.4 \%$ vs. $60.4 \%$; $<<0.001)$. The mean $\mathrm{HbA}_{1 c}$ level in the CSII-treated group was noticeably lower $(7.44 \pm 1.67 \%$ vs. $8.55 \pm 1.1 \%, \mathrm{p}<0.001)$, and these patients also had lower triglyceride levels $(0.71$ vs. $1.32 \mathrm{mmol} / \mathrm{L}, \mathrm{p}<0.001)$. Regardless of the treatment method, $72 \%$ of all patients under 40 years of age achieved their therapeutic target of LDL cholesterol level $<2.6 \mathrm{mmol} / \mathrm{L}$, whereas only $13 \%$ of all those over 40 years old achieved an LDL cholesterol level $<1.8 \mathrm{mmol} / \mathrm{L}$.

Conclusions: The presented results draw attention to the high prevalence of CAN among T1DM patients. The study reveals the need for more intensive monitoring and treatment of hyperlipidaemia, despite good glycaemic control, especially in those over the age of 40 years. (Endokrynol Pol 2019; 70 (4): 323-329)
\end{abstract}

Key words: cardiovascular autonomic neuropathy; continuous subcutaneous insulin infusion; lipoprotein profile; type 1 diabetes

\section{Introduction}

Patients with type 1 diabetes mellitus (T1DM) are at greatest risk of chronic complications of diabetes, due to total insulin dependence from the beginning of the disease and its long-term duration [1]. However, most of the research and interest of clinicians concerns chronic complications in patients with type $2 \mathrm{DM}$. The number of cardiovascular and neurological complications of DM, including diabetic neuropathy, gradually increases with time [2]. The Diabetes Control and Complications Trial (DCCT) confirmed a gradual increase in the incidence of neuropathy, almost up to $40 \%$, in patients with T1DM over the duration of the underlying disease [3]. In the EURODIAB study, $28 \%$ of T1DM patients had somatic peripheral neuropathy, and the features of diabetic autonomic neuropathy presented in $36 \%$ of the subjects [4]. A low level of metabolic control and, most of all, the occurrence of hypo- and hyperglycaemic episodes, inducing oxidative stress and the activation of immu- no-inflammatory processes, lead to the development and progression of life-threatening DM complications [5].

Cardiovascular autonomic neuropathy (CAN) manifests itself through reduced variability of the heart rhythm or orthostatic hypotension. It impairs the ability of the cardiovascular system to respond adequately to external stimuli, which significantly worsens patients' quality of life. It has been shown that subclinical CAN may increase the mortality of patients [6]. It is associated with an increase in the frequency of ventricular arrhythmia, one of the main mechanisms in the occurrence of sudden cardiac death in DM patients [6]. Additionally, there is an increased risk of death among the DM population, despite improvements in glycaemic control. It has been found that patients with well-controlled T1DM $\left(\mathrm{HbA}_{1 \mathrm{c}} \leq 6.9 \%\right)$ have a two-fold increased risk of death from all causes, including cardiovascular complications, compared to the control group [7].

In order to optimise the evaluation of CAN, the Ewing test is commonly used. It assesses the function of 
the parasympathetic system (the variability of the heart rate during the Valsalva test, deep breathing, and after changing position to orthostatic) and the sympathetic system (variation of blood pressure both in an orthostatic position and after physical exercise).

One of the elements of metabolic control for patients with DM is monitoring the lipid profile. In terms of lipid control, the DCCT study showed that cholesterol levels were similar to the control group without diabetes, as long as metabolic control was achieved [3]. A study has also been published showing a significantly higher (over $65 \%$ of the population) prevalence of lipid profile disorders in children and adolescent patients with T1DM [8]. These studies and the higher risk of cardiovascular complications in T1DM patients indicate that such patients require an intensive approach to lipid treatment.

Considering the various results of reports on the significance of metabolic compensation in the prevention of cardiovascular complications in DM patients, the present study evaluated metabolic control (glycaemic and lipid levels) obtained using two different kinds of insulin therapy (MDI and CSII) and the prevalence of CAN in T1DM patients without a positive history of ischaemic heart disease.

\section{Material and methods}

This study is a retrospective analysis of a group of 93 adult patients (60 women, $33 \mathrm{men}$ ), selected from a total of 162 T1DM patients who underwent diagnostic tests for CAN, treated in a local clinical centre from 2011 to 2015 . The study included people with T1DM (confirmed with a positive anti-GAD antibody test), whose age at the onset of the disease was $<40$ years and in whom the duration of the disease exceeded five years. The exclusion criteria for the analysis were age at the onset of the disease $>40$ years, duration of DM of $<5$ years, pregnancy, and neoplastic diseases.

All the patients underwent a detailed physical examination (age, weight, height, BMI, age at which T1DM was diagnosed, and its duration). The form of diabetes treatment was established: continuous subcutaneous insulin infusion (CSII) or multiple daily subcutaneous injections (MDI). Using fasting venous blood tests (glycaemia, lipid profile, and levels of $\mathrm{HbA}_{1 \mathrm{c}^{\prime}}$ creatinine, and TSH), biochemical determinations of metabolic control were performed and its possible complications assessed. The albumin-to-creatinine ratio was checked using morning urine samples. Biochemical tests were performed at the main laboratory diagnostics department in the hospital, in accordance with standard procedures. In the lipid profile, total cholesterol, LDL, HDL, and triglycerides were tested. Non-HDL-cholesterol was calculated using the following formula: non-HDL-C = total cholesterol - HDL. Achievement of lipid level targets were analysed in our study by taking into consideration both LDL and non-HDL cholesterol levels for a complete evaluation. The diagnosis and evaluation of diabetic kidney disease was performed in accordance with the Kidney Disease Outcomes Quality Initiative (KDOQI), through the assessment of albumin excretion in urine and the eGFR according to the MDRD formula [9]. The diagnosis of Hashimoto thyroiditis was based on a combination of clinical features, the presence of serum antibodies against thyroid antigens, and the appearance on a thyroid sonogram.

To assess the severity of the symptoms of CAN, recommended diagnostic methods were used, such as the Ewing test [10, 11], performed with ProSciCard apparatus (Mewicon CATEEM-Tec $\mathrm{GmbH}, \mathrm{Tab}$. I). Non-invasive functional tests were performed in the morning, on an empty stomach, in patients who had been fasting for a minimum of six hours. Patients did not drink alcohol or smoke in the 12 hours prior to the study. Medications that could affect autonomic functions (such as $\beta$-blockers, anticholinergics, antihistamines) were discontinued prior to testing, where possible. The set of tests carried out included the Valsalva test, a deep breath test, an orthostatic test, and the analysis of sinus rhythm variability. CAN was diagnosed when at least three tests were abnormal.

Table I. Evaluation of autonomic cardiovascular function - Ewing's test

\begin{tabular}{|c|c|c|c|}
\hline & Normal & Borderline & Abnormal \\
\hline PNS & \multicolumn{3}{|c|}{ Variation of HR } \\
\hline Valsalva test (Valsalva coefficient) & $\geq 1.21$ & $1.11-1.20$ & $\leq 1.10$ \\
\hline Deep breathing (max/min HR; beats/min) & $\geq 15$ & $11-14$ & $\leq 10$ \\
\hline $\begin{array}{l}\text { Orthostasis coefficient } 30: 15 \text {; } \\
\text { (R-R variability) }\end{array}$ & $\geq 1.04$ & $1.01-1.03$ & $\leq 1.00$ \\
\hline SNS & \multicolumn{3}{|c|}{ Variability of BP } \\
\hline Orthostasis (reduction in SBP, mm Hg) & $\leq 10$ & $11-29$ & $\geq 30$ \\
\hline Exercise (increase in DBP, mm Hg) & $\geq 16$ & $11-15$ & $\leq 10$ \\
\hline Valsalva coefficient & \multicolumn{3}{|c|}{$\begin{array}{l}\text { The quotient of the maximum R-R interval of the ECG curve in phase } 4 \text { of the Valsalva trial (increase } \\
\text { BP above the values determined before the test with subsequent bradycardia) to the minimal R-R } \\
\text { interval in phase } 2-3 \text {. (phase } 2 \text { : lowering BP followed by its normalisation, accompanied by an } \\
\text { acceleration of cardiac function, phase } 3 \text { : increase in BP with cardiac acceleration) (RR max [4]/RR } \\
\text { min [2-3]). Phase } 1 \text { of the Valsalva trial involves a transient increase in BP and a reduction in pulse } \\
\text { rate as a result of increased blood flow to the peripheral circulation }\end{array}$} \\
\hline Orthostasis coefficient 30:15 & \multicolumn{3}{|c|}{$\begin{array}{l}\text { The quotient of the maximum RR interval of around } 30 \text { (usually } 21-45 \text { ) HB to the minimum } R R \\
\text { interval of about } 15 \text { (usually } 5-25 \text { ) HB after upright positioning (RR max [21-45]/RR min [5-25]) }\end{array}$} \\
\hline
\end{tabular}

PNS — parasympathetic nervous system; SNS — sympathetic nervous system; HB — heart beat; HR — heart rate; SBD — systolic blood pressure; DBP — diastolic blood pressure; BP — blood pressure 
The results were subjected to statistical analysis using Student's t-test or U-Mann-Whitney test and a one-factor and logistic regression analysis. The normality of distribution of continuous variables was tested using the Shapiro-Wilk test. Continuous variables with normal distribution were presented as the mean \pm standard deviation (SD); non-normal variables were reported as the median. For selected variables, multivariate regression analysis was performed using the following independent variables: age, duration of diabetes, glycaemia, $\mathrm{HbA}_{1{ }^{\prime}}$ presence of chronic kidney disease, $\mathrm{BMI}$, LDL, HDL, TG, and non-HDL-C. A $\chi^{2}$ test or Fisher's test was used for qualitative data.

Descriptive statistics, including the mean and SD for continuous data, as well as frequency and proportions for qualitative data, were used to describe the characteristics of groups. Statistical significance was set at $\mathrm{p}<0.05$. The statistical analysis was conducted using $\mathrm{R}$ software (ver. 3.2.4).

\section{Results}

A total of 93 people qualified for the further analysis of this study: 60 women (62.5\%) and 33 men (37.5\%). The patients' mean age at the time of the study was 31 years (18-66). The median duration of diabetes was 16 years; the median age of onset was 13 years. The occurrences of comorbidities and other chronic complications of DM were analysed. The presence of Hashimoto's disease was found in $29.2 \%$ of the tested group, and its occurrence was not related to the duration of DM $(\mathrm{p}=0.44)$. Kidney damage characterised by low creatinine clearance $<60 \mathrm{~mL} / \mathrm{min}$ (stage $\geq 3$ KDIGO) and/or albuminuria $\geq 30 \mathrm{mg} / \mathrm{mmol}$ [10] appeared in $24.8 \%$ of patients. The clinical characteristics of the whole tested group are shown in Table II.

Of the examined patients, 57 people $(61 \%)$ were using MDI, and the rest (39\%) were using CSII. The daily insulin dose (41 U vs. $45 \mathrm{U}$ ) in both analysed groups did not differ significantly. The mean duration of diabetes (13.8 \pm 4.7 vs. $18.9 \pm 10$ years, $\mathrm{p}<0.007)$ was lower

Table II. Clinical characteristics of study participants with type 1 diabetes mellitus (T1DM) $(n=93)$

\begin{tabular}{lc}
\hline Parameter & Prevalence \\
\hline Sex (F/M) \% & $64.5 / 35.5$ \\
\hline Age (years) & $18-66$ (median 31) \\
\hline Duration of diabetes (years) & $5-44$ (median 16) \\
\hline Weight $[\mathrm{kg}]$ & $44-100$ (mean 67.3 \pm 12$)$ \\
\hline Height $[\mathrm{cm}]$ & $152-187$ (median 167) \\
\hline BMl $\left[\mathrm{kg} / \mathrm{m}^{2}\right]$ & $14.8-33.6$ (median 23.2) \\
\hline HbA ${ }_{1 \mathrm{c}}(\%)$ & $5.9-12.9$ (median 7.8) \\
\hline Hashimoto disease prevalence & $29.2(\%)$ \\
\hline $\mathrm{C}_{\mathrm{kr}}<60 \mathrm{~mL} /$ min & $6.50(\%)$ \\
\hline Albuminuria $\geq 30 \mathrm{mg} / \mathrm{d}$ & $21.50(\%)$ \\
\hline BMl - body mass index; $\mathrm{HbA}_{1 \mathrm{c}}-$ glycated hemoglobin; $\mathrm{C}_{\mathrm{kr}}-$ creatinine \\
clearance
\end{tabular}

in the group treated with CSII. At the same time, the mean age of patients in the group treated with CSII was lower compared to patients using MDI (27.6 \pm 9.1 vs. $40.6 \pm 12.2$ years, $\mathrm{p}<0.001)$. The level of $\mathrm{HbA}_{1 \mathrm{c}}$ in the CSII group was considerably lower compared to the MDI group $(7.44 \pm 1.67 \%$ vs. $8.55 \pm 1.1 \%, \mathrm{p}<0.001)$.

In the examined group of patients, the lipid profile was assessed based on the 2016 ESC/EAS guidelines: a therapeutic target of LDL cholesterol levels of $<2.6 \mathrm{mmol} / \mathrm{L}$ for people under 40 years of age and $<1.8 \mathrm{mmol} / \mathrm{L}$ for older patients [13]. This criterion was met by $72 \%$ and $13 \%$ of the respective groups. The percentage of people who had achieved target non-HDL-C level was also assessed. In the group $<40$ years of age $90.3 \%$ met the standards (non-HDL-C $<3.4 \mathrm{mmol} / \mathrm{L}$ ), and in the group $\geq 40$ years of age $29.2 \%$ of patients were within the reference range (non-HDL-C $<2.6 \mathrm{mmol} / \mathrm{L}$ ).

The analysis of individual lipidogram fractions showed a significantly higher triglyceride level in patients $<40$ years of age:

- with diagnosed CAN vs. without ( $\mathrm{p}<0.02$, Tab. III);

— treated with MDI vs. CSII ( $\mathrm{p}<0.002$, Tab. IV).

Of the T1DM patients studied, $41 \%(\mathrm{n}=38)$ presented with CAN. Upon evaluating the studied population's treatments of T1DM, it was found that CAN was notably more frequent in the subset of MDI patients compared with CSII (60.4\% vs. 15.4\%, p < 0.001, Fig. 1).

It was also shown that people who were diagnosed with CAN had a longer duration of T1DM than those who were not $(22.1 \pm 9.6$ years $v s .15 .2 \pm 6.8$ years, $\mathrm{p}<0.001)$. Concurrently, $\mathrm{HbA}_{1 \mathrm{c}}$ levels were substantially higher in patients with T1DM complicated by CAN compared to the group without CAN $(8.62 \pm 1.72 \%$ vs. $7.78 \pm 1.39 \%$, $\mathrm{p}<0.01$, Tab. IV). However, the level of diabetes control $\left(\mathrm{HbA}_{1 \mathrm{c}}\right.$ level) did not correlate with the duration of T1DM ( $\mathrm{p}=0.21)$. In multivariate analysis significant parameters for the development of CAN were included.

When considering treatment method, age, duration of DM, metabolic control ( $\mathrm{HbA}_{1 \mathrm{c}}$ and HDL level), and the presence of kidney failure, multivariate regression analysis of the occurrence of CAN confirmed a significant relationship between CAN and the following factors:

- duration of DM $(\mathrm{p}=0.02)$;

- HDL level ( $p=0.04)$;

- diagnosed kidney failure $(\mathrm{p}=0.01)$;

but no significant relationship with the following:

— treatment with CSII $(\mathrm{p}=0.99)$;

- age $(\mathrm{p}=0.57)$;

- $\mathrm{HbA}_{1 \mathrm{c}}$ level $(\mathrm{p}=0.18$, Tab. V). 
Table III. Characteristics of type 1 diabetes mellitus (T1DM) patients regarding the occurrence of cardiovascular neuropathy $(n=93)$

\begin{tabular}{lccc}
\hline Parameter & CAN (+) & CAN (-) & Significance \\
\hline DM duration (years) & $22.1 \pm 9.60$ & $15.24 \pm 6.84$ & $\mathbf{p}<\mathbf{0 . 0 0 1}$ \\
\hline $\mathrm{HbA}_{1 \mathrm{c}}(\%)$ & $8.62 \pm 1.72$ & $7.78 \pm 1.39$ & $\mathbf{p}<\mathbf{0 . 0 1}$ \\
\hline Lipidogram [mmol/L] & & \\
\hline Total cholesterol & $4.22 \pm 0.85$ & $4.43 \pm 0.83$ & $\mathrm{p}=0.33$ \\
\hline LDL-C & $2.37 \pm 0.76$ & $2.47 \pm 0.76$ & $\mathrm{p}=0.57$ \\
\hline Non-HDL-C & $2.54 \pm 1.13$ & $2.00 \pm 1.50$ & $\mathrm{p}=0.15$ \\
\hline TG & & & $\mathbf{p}<\mathbf{0 . 0 2}$ \\
$<40$ y.o. & $1.27 \pm 0.91$ & $0.86 \pm 0.44$ & $\mathrm{p}=0.82$ \\
\hline 40 y.o. & $1.40 \pm 1.14$ & $1.43 \pm 1.14$ & \\
\hline
\end{tabular}

CAN (+) - T1DM patients who developed cardiovascular autonomic neuropathy; CAN (-) — T1DM patients without cardiovascular autonomic neuropathy; $\mathrm{DM}$ — diabetes mellitus; $\mathrm{HbA}_{1 \mathrm{c}}$ — glycated hemoglobin; $\mathrm{LDL}$ — low density lipoprotein; TG — triglycerides

Table IV. Characteristics of metabolic control in patients with type 1 diabetes mellitus $(T 1 D M)(n=93)$ treated with continuous subcutaneous insulin infusion (CSII) $(n=36)$ and multiple daily subcutaneous injections $(M D I)(n=57)$

\begin{tabular}{lccc}
\hline Parameter & CSII & MDI & Significance \\
\hline Age (years) & $25.94 \pm 5.99$ & $38.4 \pm 11.32$ & $\mathbf{p}<\mathbf{0 . 0 0 1}$ \\
\hline $\mathrm{HbA}_{1 \mathrm{c}}(\%)$ & $7.44 \pm 1.14$ & $8.55 \pm 1.67$ & $\mathbf{p}<\mathbf{0 . 0 0 1}$ \\
\hline Lipidogram [mmol/L] & & & $\mathbf{p}<\mathbf{0 . 0 5}$ \\
\hline Total cholesterol & $4.02 \pm 0.6$ & $4.45 \pm 0.89$ & $\mathrm{p}=0.57$ \\
\hline LDL-C & $2.07 \pm 0.53$ & $2.57 \pm 0.79$ & $\mathbf{p}<\mathbf{0 . 0 0 1}$ \\
\hline Non-HDL-C & $1.28 \pm 1.32$ & $2.82 \pm 1.06$ & $\mathbf{p}<\mathbf{0 . 0 0 2}$ \\
\hline TG & & & not applicable \\
\hline 40 years old & $0.70 \pm 0.19$ & $1.25 \pm 0.82$ & $1.43 \pm 1.14$ \\
\hline 40 years old & 1 [one person] &
\end{tabular}

$\mathrm{HbA}_{1 \mathrm{c}}$ — glycated hemoglobin; LDL — low density lipoprotein; $\mathrm{HDL}$ — high density lipoprotein; TG — triglycerides

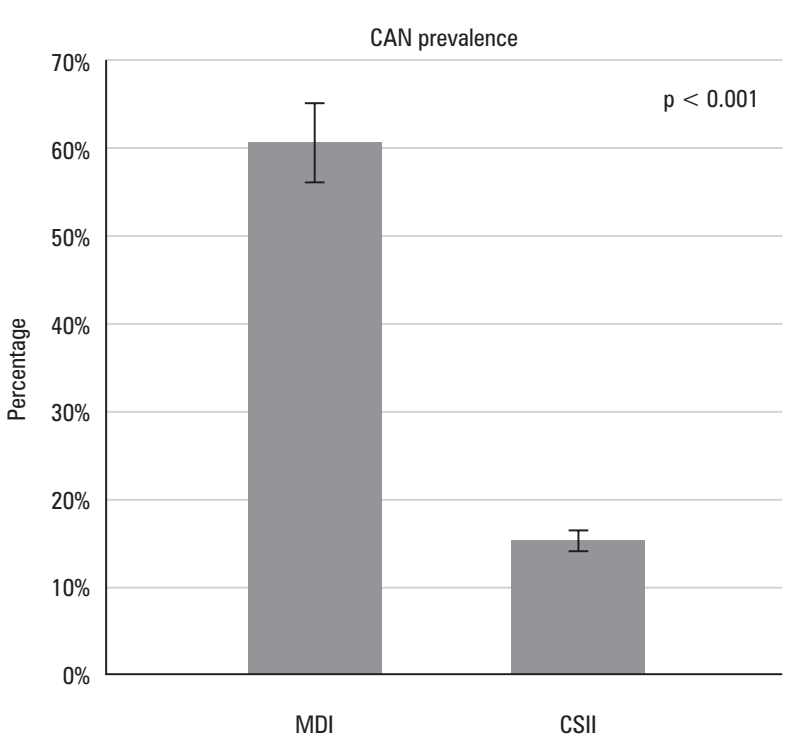

Figure 1. Prevalence of cardiovascular autonomic neuropathy in a group of patients with type 1 diabetes mellitus (T1DM) treated with multiple daily subcutaneous injections (MDI) $(n=57)$ vs. patient treated with continuous subcutaneous insulin infusion (CSII) $(n=36)(p<0.001)$

\section{Discussion}

To our knowledge, this is the first study of a group of patients with T1DM, their lipid targets, and the occurrence of CAN, which considers metabolic control and the method of insulin therapy used. A few years ago, a draft register of diabetic patients included patients with T1DM but focused mostly on the quality of diabetes care in all patients [12]. Nevertheless, the authors emphasised the lack of metabolic control optimisation, including the level of lipids, in patients with various types of diabetes (T1DM, T2DM, GDM).

It is believed that CSII enables better physiological control over insulin dosage. This should translate into an improvement in metabolic control in T1DM patients, such as a better glycaemic level or lipid profile [13]. In the presented analysis, the level of $\mathrm{HbA}_{1 \mathrm{c}}$ was significantly lower in the CSII group compared to the group treated using MDI. This observation is consistent with reports from other centres in which a significant reduction in level of $\mathrm{HbA}_{1 \mathrm{c}}$ was demonstrated just a few months after 
Table V. The association between different clinical variables and cardiovascular autonomic neuropathy in diabetes type 1 patients, the multivariate logistic regression-derived odds ratios (OR) [and 95\% confidence intervals (CI)], statistical significance $p<0.05$

\begin{tabular}{lccc}
\hline Parameter & OR & $\mathbf{9 5 \%}$ Cl & p \\
\hline CSIl usage (YES) & 0.99 & $0.21-4.61$ & 0.99 \\
\hline Age (years) & 0.98 & $0.92-1.05$ & 0.57 \\
\hline Diabetes duration (years) & 1.11 & $1.02-1.23$ & $\mathbf{0 . 0 2}$ \\
\hline $\mathrm{HbA}_{1 \mathrm{c}}(\%)$ & 1.33 & $0.88-2.06$ & 0.18 \\
\hline $\mathrm{HDL}[\mathrm{mmol} / \mathrm{L}]$ & 0,22 & $0.04-0.81$ & $\mathbf{0 . 0 4}$ \\
\hline Presence of kidney failure (YES) & 7.85 & $1.86-43.24$ & $\mathbf{0 . 0 1}$ \\
\hline
\end{tabular}

CSII — continuous subcutaneous insulin infusion; $\mathrm{HbA}_{1 \mathrm{c}}$ — glycated hemoglobin; $\mathrm{HDL}$ - high density lipoprotein

the implementation of pump therapy $[13,14]$. At the same time, regardless of the T1DM treatment method, we observed significantly worse metabolic control in patients with CAN in terms of $\mathrm{HBA}_{1 \mathrm{c}}$ level. A similar relationship was found in the DCCT study, in which it was shown that more intensive treatment of diabetes and better metabolic control had a preventive effect on the development of complications [15].

In the present study, there was a notably lower proportion of patients with CAN in the group treated with CSII. This significant difference is due to better glycaemic control and the shorter duration of the disease, and was not directly related to the therapy method itself. It is worth noting that, according to the guidelines of Diabetes Poland [16] and ADA [17], the first assessment for neuropathy in a patient with T1DM should be conducted five years after the onset of diabetes. However, Pfeifer et al. showed that people with T1DM, even after the first two years of the disease, may present early stages of CAN expressed by a reduction in the $\mathrm{RR}$ interval variation during $\beta$-adrenergic blockade [18].

Until now, the pathogenesis of diabetic neuropathy has not been clearly established. Two main theories are recognised in the pathogenesis of this disease: metabolic and ischaemic [19]. Our observations refer to the first of them, according to which the excess of glucose is transformed by aldose reductase into sorbitol and then into fructose. The accumulation of these compounds in neurons due to osmotic effects, oxidative stress, and the generation of free radicals causes a decrease in the biosynthesis of metabolites necessary for the functioning of the nerve cell and leads to apoptosis [20].

A rise in the frequency of CAN increases mortality caused by cardiac arrhythmias, especially of ventricular origin, and episodes of silent myocardial ischaemia [21]. In addition, diabetes is a known, independent risk factor for coronary heart disease, predisposing to severe and disseminated atherosclerotic lesions in vessels [22]. The whole picture argues for the necessity of permanent supervision of cardiac patients with T1DM, in whom, regardless of the method of treatment, there is a significant percentage of overt, chronic metabolic complications significantly increasing the risk of death.

In this study, when analysing lipidogram results, unsatisfactory lipid control was found. LDL-cholesterol level is one of the most important, independent factors promoting atherosclerosis, but it is still found not to be properly treated. Although a high percentage of patients in the $<40$ years age group was within therapeutic targets, as much as $87 \%$ of the population of older patients ( $>40$ years old) had an abnormal LDL level. Furthermore, patients with a chronic disease such as diabetes, who are in constant contact with a family doctor at least to obtain prescriptions for insulin, are not adequately supervised for lipid disturbances. Non-HDL cholesterol was found to be elevated in over $70 \%$ of patients $>40$ years old, but its role in T1DM has not been established yet.

Previous studies on the lipid profile analysis of patients with DM concerned mainly type $2 \mathrm{DM}$, where the importance of abnormalities in the lipid profile in the aetiopathogenesis of cardiovascular diseases has been confirmed [23]. Published studies on lipid profile assessments in patients with T1DM in relation to a control group without diabetes showed significantly lower levels of analysed parameters in patients with T1DM [24]. New data are expected soon from the completed Adolescent type 1 Diabetes cardio-renal Intervention Trial (AdDIT) to provide information about potential renal and cardiovascular protective effects of ACEI and statins in high-risk adolescents [25]. For now, the assessment of risk of cardiovascular complications is similar for both types of diabetes. Collins provided direct evidence that statin therapy is beneficial for diabetic patients even if they do not have clear signs of coronary disease or high cholesterol concentrations, which suggests that cholesterol-lowering drugs should be considered as routine therapy for all diabetic patients irrespective of their initial cholesterol level, to prevent 
the development of angioneuropathy [26]. In addition, recent observations regarding an abnormal lipid profile in children and adolescents with T1DM emphasise the important role of monitoring this parameter in medical care for all patients with T1DM [8]. We showed a statistically significant relationship between the use of CSII and lower triglyceride levels, which is probably related to decreased lipolysis in better controlled DM patients [27]. Our results draw attention to this problem for the first time and indicate the need for more intensive monitoring and treatment of hyperlipidaemia, especially LDL, in adult patients mainly over the age of 40 years.

The presented study is a retrospective observation. The relatively small group of participants weakens the power of the work. However, it should be remembered that these are patients with T1DM, who constitute a homogeneous group from the southern region of Poland, which reduces the impact of disturbing environmental factors. In accordance with earlier reports, in our examined group better metabolic control was achieved with CSII, which confirms the high value of new technologies in T1DM treatment. However, the lack of a relationship between CAN and treatment method in multivariate regression analysis might be due to the younger age range and the shorter duration of the disease in patients treated with CSII. This results from economic conditions and reflects the real profile of the treatment method for patients in our society. Since 2009, the National Health Fund (NFZ) has financed the purchase of insulin pumps for children and adolescents up to 18 years of age, and since 2011 this limit has been raised to 26 years of age. The shorter average duration of treatment using personal pumps vs. insulin pens is due to the fact that these devices have been available in clinics for a much shorter time than therapy with pens.

\section{Conclusions}

In conclusion one innovative point in our study is that it draws attention to the need for comprehensive and accurate monitoring of patients with T1DM in terms of CAN risk, due to the very high prevalence of cardiovascular complications in such patients. It confirms the beneficial effect of glycaemic control, and, at the same time, draws attention to the non-optimised treatment of lipids, which intensifies the mechanisms for the development of angioneuropathy. Our results also highlight the need for clinicians to monitor overall metabolic control in patients with T1DM, even those who have not yet developed the chronic complications of diabetes but have reached the age of about 40 years. Proper and comprehensive care of patients with T1DM requires, in addition to measuring the level of glycaemia, regular (minimum once a year) biochemical monitoring of other parameters of metabolic control.

\section{Author contribution}

LP and JG contributed equally to the current work.

\section{Conflict of interest}

Authors declare no conflict of interest.

\section{Acknowledgements}

This work was co-financed thanks to a scientific grant from the National Science Centre (UMO-2014/13/ /B/NZ4/00149).

\section{References}

1. Laing SP, Swerdlow AJ, Slater SD, et al. Mortality from heart disease in a cohort of 23,000 patients with insulin-treated diabetes. Diabetologia. 2003; 46(6): 760-765, doi: 10.1007/s00125-003-1116-6, indexed in Pubmed: 12774166

2. Apfel SC. Introduction to diabetic neuropathy. Am J Med. 1999; 107(2B): 1S, indexed in Pubmed: 10484038.

3. The Diabetes Control and Complications Trial Research Group. The effect of intensive diabetes therapy on the development and progression of neuropathy. The Diabetes Control and Complications Trial Research Group. Ann Intern Med. 1995; 122(8): 561-568, indexed in Pubmed: 7887548.

4. Kempler P, Tesfaye S, Chaturvedi N, et al. EURODIAB IDDM Complications Study Group, EURODIAB IDDM Complications Study Group. Autonomic neuropathy is associated with increased cardiovascular risk factors: the EURODIAB IDDM Complications Study. Diabet Med. 2002; 19(11): 900-909, indexed in Pubmed: 12421426.

5. Kiec-Wilk B, Matejko B, Razny U, et al. Hypoglycemic episodes are associated with inflammatory status in patients with type 1 diabetes mellitus. Atherosclerosis. 2016; 251: 334-338, doi: 10.1016/j.atherosclerosis.2016.05.002, indexed in Pubmed: 27237074.

6. StanczykJ, Deja G. Neuropatia autonomiczna układu sercowo-naczyniowego oraz zaburzenia ciśnienia tętniczego krwi u dzieci z cukrzycą typu 1. Nowa Pediatria. 2007; 16(2): 30-34.

7. Maser RE, Mitchell BD, Vinik AI, et al. The association between cardiovascular autonomic neuropathy and mortality in individuals with diabetes: a meta-analysis. Diabetes Care. 2003; 26(6): 1895-1901, indexed in Pubmed: 12766130.

8. Zabeen B, Balsa AM, Islam N, et al. Lipid Profile in Relation to Glycemic Control in Type 1 Diabetes Children and Adolescents in Bangladesh. Indian J Endocrinol Metab. 2018; 22(1): 89-92, doi: 10.4103/ijem. IJEM_217_17, indexed in Pubmed: 29535944.

9. National Kidney Foundation. KDOQI Clinical Practice Guideline for Diabetes and CKD: 2012 Update. Am J Kidney Dis. 2012; 60(5): 850-886, doi: 10.1053/j.ajkd.2012.07.005, indexed in Pubmed: 23067652.

10. Boulton AJM, Vinik AI, Arezzo JC, et al. American Diabetes Association, American Diabetes Association. Diabetic neuropathies: a statement by the American Diabetes Association. Diabetes Care. 2005; 28(4): 956-962, indexed in Pubmed: 15793206.

11. Szczyrba S, Kozera G, Bieniaszewski L, et al. Neuropatia cukrzycowa - patogeneza, rozpoznawanie, zapobieganie, leczenie. Forum Medycyny Rodzinnej. 2010; 4(5): 339-355.

12. Witek P, Wołkow P, Stancel-Mozwillo J, et al. The Polish Diabetes Registry for Adults — a pilot study. Diabetologia Kliniczna. 2012; 1(1): 3-11.

13. Doyle EA, Weinzimer SA, Steffen AT, et al. A randomized, prospective trial comparing the efficacy of continuous subcutaneous insulin infusion with multiple daily injections using insulin glargine. Diabetes Care. 2004; 27(7): 1554-1558, indexed in Pubmed: 15220227.

14. Derosa G, Maffioli P, D'Angelo A, et al. Effects of insulin therapy with continuous subcutaneous insulin infusion (CSII) in diabetic patients: comparison with multi-daily insulin injections therapy (MDI). Endocr J. 2009; 56(4): 571-578, indexed in Pubmed: 19352055.

15. The Diabetes Control and Complications Trial Research Group. The effect of intensive diabetes therapy on measures of autonomic nervous system function in the Diabetes Control and Complications Trial (DCCT). Diabetologia. 1998; 41(4): 416-423.

16. Guidelines on the management of diabetic patients. A position of Diabetes Poland. Clinical Diabetology. 2017; 6(suppl. A): 0001, doi: 10.5603/DK.2017.0001. 
17. American Diabetes Association. Standards of Medical Care in Diabetes 2017. Diabetes Care. 2017; 40(Suppl. 1): S4-SS16, doi: 10.2337/dc17-S001.

18. Pfeifer MA, Weinberg CR, Cook DL, et al. Autonomic neural dysfunction in recently diagnosed diabetic subjects. Diabetes Care. 1984; 7(5): 447-453, indexed in Pubmed: 6499637.

19. Schreiber AK, Nones CFm, Reis RC, et al. Diabetic neuropathic pain: Physiopathology and treatment. World J Diabetes. 2015; 6(3): 432-444, doi: 10.4239/wjd.v6.i3.432, indexed in Pubmed: 25897354.

20. Brownlee M. Biochemistry and molecular cell biology of diabetic complications. Nature. 2001; 414(6865): 813-820, doi: 10.1038/414813a, indexed in Pubmed: 11742414.

21. Pop-Busui R, Evans GW, Gerstein HC, et al. Action to Control Cardiovascular Risk in Diabetes Study Group. Effects of cardiac autonomic dysfunction on mortality risk in the Action to Control Cardiovascular Risk in Diabetes (ACCORD) trial. Diabetes Care. 2010; 33(7): 1578-1584, doi: 10.2337/dc10-0125, indexed in Pubmed: 20215456.

22. Rousan TA, Pappy RM, Chen AY, et al. Impact of diabetes mellitus on clinical characteristics, management, and in-hospital outcomes in patients with acute myocardial infarction (from the NCDR). Am J Cardiol. 2014; 114(8): 1136-1144, doi: 10.1016/j.amjcard.2014.07.031, indexed in Pubmed: 25150136.
23. Tohidi M, Hatami M, Hadaegh $\mathrm{F}$, et al. Lipid measures for prediction of incident cardiovascular disease in diabetic and non-diabetic adults: results of the 8.6 years follow-up of a population based cohort study. Lipids Health Dis. 2010; 9: 6, doi: 10.1186/1476-511X-9-6, indexed in Pubmed: 20096127.

24. Bervoets L, Massa G, Guedens W, et al. Metabolic profiling of type 1 diabetes mellitus in children and adolescents: a case-control study. Diabetol Metab Syndr. 2017; 9: 48, doi: 10.1186/s13098-017-0246-9, indexed in Pubmed: 28674557

25. Adolescent type 1 Diabetes cardio-renal Intervention Trial Research Group. Adolescent type 1 Diabetes Cardio-renal Intervention Trial (AdDIT). BMC Pediatr. 2009; 9: 79, doi: 10.1186/1471-2431-9-79, indexed in Pubmed: 20017932.

26. Collins R, Armitage J, Parish S, et al. Heart Protection Study Collaborative Group. MRC/BHF Heart Protection Study of cholesterol-lowering with simvastatin in 5963 people with diabetes: a randomised placebo-controlled trial. Lancet. 2003; 361(9374): 2005-2016, indexed in Pubmed: 12814710.

27. Arner P, Engfeldt P, Ostman J. Blood glucose control and lipolysis in diabetes mellitus. Acta Med Scand. 1980; 208(4): 297-299, indexed in Pubmed: 7004094. 